Centar za naučnoistraživački rad https://doi.org/10.18485/ Filološko-umetnički fakultet Univerzitet u Kragujevcu

\title{
UPOTREBA I POLOŽAJ ZAMENICE SI UZ MODALNE GLAGOLE U ITALIJANSKOM JEZIKU ${ }^{1}$
}

Osnovni cilj ovog rada je ispitivanje položaja, upotrebe i funkcije zamenice si u italijanskom jeziku. Zadatak analize je ukazivanje na koherentnost upotrebe zamenice si u delima koja ćemo analizirati i da se pobliže obradi upotreba i položaj zamenice si uz modalne glagole, uz navođenje ukupnog broja primera enklitičke i proklitičke pozicije za svaku navedenu upotrebu zamenice si u analiziranim delima. Fokusirajući se na gramatička pravila u italijanskom jeziku, zaključićemo da li je stil pisanja odabranih autora u potpunoj saobraznosti s normama italijanskog jezika. U radu ćemo pregledno izložiti upotrebu i funkcije klitika, modalnih glagola i zamenice $s i$.

Ključne reči: italijanski jezik, bezlično $s i$, povratno $s i$, pasivno $s i$, modalni glagoli.

\section{Uvod}

U ovom radu se bavimo klitikom si, odnosno zamenicom si i njenim funkcijama. Naime, ispitujemo upotrebu i položaj zamenice si u funkciji bezlične, pasivne i povratne, u korpusu koji je sastavljen iz dva književna dela: Pape Satàn Aleppe (Pape Satàn Aleppe) autora Umberta Eka (2016) i Danubio (Dunav) Klaudija Magrisa (2006). Budući da zamenica si može menjati svoj položaj u odnosu na glagol,

* jovana.bazic@filum.kg.ac.rs

1 Rad je nastao u okviru projekta Dinamika struktura savremenog srpskog jezika 178014, koji finansira Ministarstvo prosvete, nauke i tehnološkog razvoja Republike Srbije. 
u zavisnosti od glagola koji sledi, ${ }^{2}$ ispitujemo položaj zamenice si i određujemo frekventnost njenog položaja na osnovu numeričkih podataka iz korpusa. U elektronskom korpusu koji je predmet naše analize, pokušaćemo da istražimo i prikažemo primere u kojima se zamenica si upotrebljava i ispitaćemo njen položaj u odnosu na modale. Takođe, izdvojićemo neke osnovne karakteristike klitika sa kojima ćemo se susretati u analizi primera, a koji su suštinski važni za naše istraživanje. Polazimo od gramatičkog pravila da povratno si češće stoji u proklitičkom položaju kao nenaglašena zamenica, a da se naglašena povratna zamenica za 3. lice jednine sé češće nalazi u enklitičkom položaju. Bezlično i pasivno si najčešće nalazimo u proklitičkom položaju jer one markiraju odsustvo subjekta i moraju da se nađu na mestu koje „pripada“ subjektu, ispred glagola. Očekivano je da kao klitike stoje odmah do glagola.

\section{Zamenica si i modalni glagoli u italijanskom jeziku}

U italijanskom jeziku klitike su nenaglašene zamenice ili priloške rečce koje se oslanjaju na glagol, a to su: $m i, t i, g l i, l o, l a$, li, le, ci, vi, si, ne. Kada klitike prethode glagolu, pišu se rastavljeno od glagola i tada se one nazivaju proklitike. Ukoliko se nalaze posle glagola, pišu se sastavljeno i tada postaju enklitike. Klitike se međusobno mogu kombinovati tako da formiraju grupe klitika (npr. Daglielo - Daj mu ga).

Nenaglašena zamenica za 3. lice (ženski i muški rod, jednina i množina) si pre svega poprima funkciju povratne zamenice. U svojoj prvobitnoj funkciji upotrebljava se u građenju povratnih glagola, koji mogu biti direktni i indirektni. Sintaksički, si korelira sa subjektom u trećem licu jednine i množine i tako vrši službu direktnog objekta, dok glagol iskazuje radnju koju subjekat vrši na sebi, on je istovremeno i subjekat i objekat radnje: Lui si veste - On se oblači / Lui veste sé stesso - On oblači sebe. Ukoliko je u rečenici leksički iskazan direktni objekat, klitika si poprimiće funkciju indirektnog objekta.

2 Glagoli mogu da stoje u indikativu, konjunktivu, kondicionalu, imperativu, infinitivu, participu, gerundiju. 
Tokom našeg istraživanja nailazimo i na pojam penjanje klitika (risalita del clitico) koji se često može naći uz oblike imperativa (Non preoccuparti - Nemoj da se brineš / Non ti preoccupare) ${ }^{3}$ i uz modalne glagole (Te lo dovevo dire - To sam morao da ti kažem / Dovevo dirtelo - Morao sam to da ti kažem). Treba istaći i činjenicu da u italijanskom jeziku postoje tzv. pronominalni glagoli, koji se beleže kao zasebne odrednice jer u njihovu morfologiju ulaze pojedine klitike: avercela, esserci, andarci, cercarsela, passarsela, metterci, volerci, andarsene, cavarsela, prendersela i drugi (Mazini 2015: 4).

Govoreći o pronominalnim glagolima, treba izdvojiti i ukratko približiti modalne glagole, na osnovu kojih ćemo obaviti naše istraživanje. Modalni glagoli (verbi modali) u italijanskom jeziku su: dovere (morati, trebati), potere (moći, smeti), volere (hteti, želeti) i sapere (umeti, znati) (Moderc 2006: 280). Treba napomenuti da italijanski gramatičari svrstavaju i druge glagole u listu modalnih: solere (imati običaj, običavati), desiderare (želeti), osare (smeti, usuditi se) (Simone i Amaker 1977: 7 - 12). S obzirom na činjenicu da nemaju potpuno značenje, ovi glagoli uvode infinitiv čija je funkcija da pruži semantički sadržaj glagolskoj sintagmi. Da li je radnja osnovnog glagola iskazana kao mogućnost, obaveza ili volja zavisi upravo od izbora modalnog glagola. Kod složenih vremena izbor pomoćnog glagola zavisi od toga da li posle modalnog stoji prelazan ili neprelazan glagol. Ako je glagol prelazan, particip prošli menjaće se sa avere (pomoćni glagol u italijanskom jeziku sa osnovnim značenjem imati). Kada je reč o neprelaznom glagolu, menjaće se sa essere (pomoćni glagol italijanskom jeziku sa osnovnim značenjem biti). Kada posle modalnog glagola stoji povratni glagol, moguća su dva rešenja. Položaj povratne zamenice u odnosu na glagol određuje izbor pomoćnog glagola. Ukoliko zamenica stoji na kraju glagolske grupe, menjaće se sa avere: Non ha potuto pettinarsi. Ako zamenica stoji na početku glagolske grupe, pomoćni glagol je essere: Non si è potuta pettinare.

3 Valja napomenuti da nije ispitana eventualna promena u značenju zbog jednog ili drugog položaja klitika. 


\section{Funkcije zamenice $s i$}

\section{1) Pasivna zamenica $s i$}

Dijateza ili stanje jeste jedna od osnovnih kategorija koja karakteriše glagole. Grčki termin je $\delta \iota \alpha ́ \theta \varepsilon \sigma \iota \varsigma$, a latinski genus verbi. Ona može biti: aktivna (diatesi attiva), pasivna (diatesi passiva) ili medijalna (diatesi riflessiva o media). Pasivna je ona u kojoj agens glagola nije subjekat u rečenici (Terić 2009: 114). U italijanskom jeziku pasivne strukture grade se uz pomoć glagola essere i participa prošlog glagola koji mora biti prelazan i mora imati iskazan objekat, kako bi upravo taj objekat postao subjekat pasivne rečenice. Pasiv mogu imati samo prelazni glagoli (Moderc 2006: 288). Uz pasivnu zamenicu si subjekat ne može da stoji u prvom i drugom licu, dok u građenju pasiva bez zamenice si ne postoje ova ograničenja. Subjekat stoji posle predikata (Renci, Salvi i Kardinaleti 2001: 121). Naredni primeri su preuzeti iz našeg korpusa i predstavljaju rečenice u kojima nalazimo pasivnu zamenicu si:

Danubio: Quando si è stanchi della vita, si scelgono, per liberarsene, anche mezzi inconsci e indiretti, l'infarto, il cancro. $(79,39 \%)^{4}$

Pape Satàn Aleppe: Questo cose si stavano dicendo il venerdì 15 scorso. $(8,47 \%)$

\section{2) Povratna zamenica si}

Povratna zamenica si upotrebljava se uz povratne glagole u 3 . licu jednine i množine. Postoje različite podvrste povratnih glagola, te stoga možemo reći i da povratna zamenica si ima više funkcija. Izdvajamo sledeće:

a) Pravi povratni glagoli (verbi riflessivi propri) kod kojih se povratna zamenica koristi kada subjekat vrši radnju na sebi

4 Prikazani su primeri pasivne zamenice koji ne sadrže modalne glagole, preuzeti iz našeg korpusa. Procenat smo uključili radi lakšeg lociranja primera u elektronskom korpusu. U daljem delu radu ćemo detaljnije objasniti i sam način računanja paginacije. 
(Lepski i Lepski 1998: 221).

Federico si veste - Federiko se oblači.

b) Prividno-povratni glagoli (verbi riflessivi apparenti) kod kojih pored povratne zamenice postoji i objekat.

Io mi lavo le mani - Perem ruke.

c) Uzajamno-povratni glagoli (verbi riflessivi reciproci) predstavljaju grupu kod koje se radnja uzajamno vrši između dve ili više osoba.

Maria e Paolo si abbracciano - Marija i Paolo se grle.

Ovakvu podelu povratnih glagola nalazimo kod italijanskih autora (Dardano i Trifone 2014).

U okviru ove grupe nailazimo i na podelu na jake i slabe, pri čemu su verbi reciproci forti: somigliare (ličiti), confinare (graničiti se), dok su verbi reciproci deboli: guardarsi (gledati se), stimarsi (poštovati se) (v. Miličević 2009: 287).

Navešćemo dva primera povratne zamenice $s i$ iz našeg korpusa:

Pape Satàn Aleppe: C'è però da chiedersi se la caduta del muro di Berlino sia stata la causa del collasso. (4,38\%)

Danubio: (...) l'assenza di vero sesso e di vero amore, quell'afflusso di sangue al basso ventre che sente il bisogno di nobilitarsi salendo verso l'alto ed esalando in commosso sospiro.(11,45\%)

\section{3) Bezlična zamenica $s i$}

Zamenica si upotrebljava se i u građenju bezličnih konstrukcija, odnosno u rečenicama u kojima subjekat nije određen. Bezlična zamenica si upotrebljava se za građenje bezličnih oblika glagola. Koristi se isključivo uz treće lice jednine prelaznih i neprelaznih glagola. Glagoli mogu postati bezlični ukoliko im se u trećem licu jednine doda bezlično $s i$, a često se taj bezlični oblik koristi i kao zamena za prvo lice množine (Moderc 2006: 226). Međutim, treba napomenuti da glagoli koji su izvorno bezlični (zerovalenti) ne mogu da prihvate bezlično si. To su oni glagoli koji sami mogu da čine rečenicu bez dodavanja bilo kog drugog argumenta, kao u primeru Nevica - Pada sneg (Foljato, Testa 2000: 398). 
Si pranza - Ručamo / Ruča se. (Naš primer)

Kada se pojavi neko složeno vreme pomoćni glagol je uvek essere: Abbiamo camminato tutta la giornata - Hodali smo čitav dan / Si è camminati tutta la giornata - Hodali smo čitav dan.

Particip prošli bezličnih glagola imaće završetak muškog roda u jednini ukoliko glagol zahteva pomoćni glagol avere: Abbiamo sognato a occhi aperti / Si è sognato a occhi aperti - Sanjali smo otvorenih očiju. Ukoliko zahteva pomoćni glagol essere, particip prošli imaće završetak muškog roda u množini: Siamo partiti / Si è partiti - Krenuli smo. Particip može biti i ženskog roda, ako je rod markiran. Izdvajamo dva primera bezlične zamenice si iz odabranih dela:

Danubio: Quella sintassi era anche lo specchio dell'Impero, di quel Sacro-Romano-Impero del quale ci si chiede, nel Faust goethiano, come facesse a tenersi ancora insieme. ${ }^{5}(19,50 \%)$ Pape satàn Aleppe: (...) per avere successo bisogna comportarsi un poco da Dio. ${ }^{6}(12,28 \%)$

\section{Metodologija istraživanja i analiza korpusa}

Korpus koji ćemo ispitati izabran je zato što odabrana književna dela predstavljaju ostvarenja afirmisanih pisaca i novijeg su datuma, te predstavljaju i oslikavaju savremeni italijanski književni jezik. Iščitavajući ova dela primetili smo da se položaj zamenice $s i$ uz modalne glagole u određenim primerima razlikuje od položaja u standardnom italijanskom jeziku. Za pretragu zamenice u ovom delu možemo iskoristiti nizove znakova kao što su "rsi“ i „si“ koje unosimo u polje za pretragu, obradu i analizu teksta jer koristimo

5 Valja napomenuti da se povratna zamenica si disimiluje u $c i$ ispred bezlične zamenice si koja stoji do glagola. Zbog toga ćemo tokom analize dela često nailaziti na primere poput ci si accorge, ci si è arrivati. Kod Magrisa ovakvih oblika ci si nalazimo u 54 primera, dok kod Eka u 9.

6 Na internetu nalazimo rečenicu: Come si bisogna comportare. Nalazimo primer u našem korpusu u kom je moguće tzv. penjanje kilitika (risalita del clitico), ali samo u govornom jeziku, u gramatici to nije dozvoljeno. 
elektronsku verziju dela. Mi smo se opredelili za elektronski korpus i u njemu ćemo pretraživati: „si“ sa razmakom ispred ili iza i „, s' “, ali i završni deo reči "rsi“ i to na sledeći način: „rsi“ sa razmakom; „rsi“ sa zapetom; „rsi“" sa tačkom; „rsi“ i dve tačke, „rsi“ i tačka zarez, upitnik ili uzvičnik; i najzad „- rsi“ sa crticom da se vidi da nije cela reč, početak reči ili sredina, već završetak. U radu ćemo teorijski prikazati upotrebu zamenice si u proklitičkom i enklitičkom položaju, upotrebu klitika u italijanskom jeziku, kao i primere u kojima se zamenica si javlja u svojim trima funkcijama u pomenutim delima. Zatim ćemo prikazati brojčani odnos proklitičke ili enklitičke upotrebe zamenice si i na osnovu tog podatka izvešćemo zaključak da li autori primenjuju jedan ili drugi položaj. Na kraju ćemo prikazati koliko puta je si bezlično, pasivno ili povratno.

Polazeći od gramatičkog pravila da povratno si radije stoji u proklitičkom položaju kao nenaglašena zamenica, a da bezlično i pasivno si najčešće nalazimo u proklitičkom položaju, ispitaćemo upotrebu i položaj istih kod pomenutih italijanskih pisaca u primerima koje smo izdvojili. Priložena paginacija dobija se tako što se broj stranice na kojoj se primer nalazi podeli ukupnim brojem stranica knjige i nakon toga se dobijeni broj pomnoži sa 100.

\section{Danubio}

U ovom delu rada sistematično ćemo prikazati određeni broj primera iz dela Dunav autora Klaudija Magrisa, u kojem smo zabeležili primere pasivnog, povratnog i bezličnog si uz modalne glagole.

\section{1) Pasivno si (Si passivante)}

Izdvajajući primere koji oslikavaju upotrebu i položaj pasivne zamenice si kod Magrisa pronašli smo 17 primera za proklitičko pasivno si, dok za enklitično pasivno si nismo pronašli nijedan. U ovom radu izdvojićemo sledeće primere u proklitičkom položaju uz modalne glagole: 
(1) Gli altri contadini, boschi, parole, consuetudini aldilà dei monti e dei mari, che non si potevano vedere né toccare ${ }^{7}$ ma di cui si poteva avere una conoscenza solo mediata e indiretta, diventavano astratti, ideologici, irreali (...) $(9,82 \%)$

(2) Le chiese, le torri, le case patrizie, le figure scolpite dicono la maestà del passato, una gloria che si può solo ricordare e mai possedere $e^{8}$, che è sempre stata e che non è mai. $(24,55 \%)$

(3) Nella Canzone dei Nibelunghi prevale l'amore, il legame coniugale fondato sulla libera elezione, l'inclinazione del cuore e la fedeltà scelta deliberatamente; nell' Edda domina l'ethos della stirpe, la fedeltà fatale ad un vincolo di sangue che non si può scegliere. $(29,74 \%)$

(4) Prima del 1918, i viennesi consideravano Bratislava quasi un amabile sobborgo, che si poteva raggiungere in meno di un'ora per gustare i suoi vini bianchi (...) (53,88\%)

(5) (...) gli sportelli della stazione che regola il traffico dei passeggeri sul fiume sono chiusi e una piccola folla incerta si mette vagamente in coda, senza che si sappia se e quando si potranno prendere i biglietti. (98,36\%)

Pasivnu zamenicu si uz modalne glagole pronašli smo u 17 primera. Stoga, možemo zaključiti da pisac pasivnu zamenicu si uz modalne glagole uvek stavlja u proklitički položaj.

2) Povratno si (Si riflessivo)

Sledeći primer (6) je jedini koji smo pronašli za povratno proklitičko si.

(6) Capisco, non potevi far altro, sei fatto cosi, è il tuo carattere, non si può fartene una colpa, è la vita. (56,34\%)

Posmatrajući primere koje nalazimo uz modalne glagole zapažamo da autor povratnu zamenicu si stavlja u enklitički položaj u 58 primera. Izdvojićemo sledeće:

7 Glagole vedere i toccare ćemo izdvojiti u krajnjem zbiru pronađenih primera.

8 Glagole ricordare i possedere izdvojićemo posebno, kao i u prethodnom primeru. 
(7) Egli volesse perdersi e fornire a se stesso indicazioni svianti. (2,86\%)

(8) E il vento che il viaggiatore vorrebbe, l>avventura, la cavalcata in cima alla collina; egli vorrebbe imbattersi, come Keplero Mathematicus. $(4,02 \%)$

(9) La parabola di Srbik dimostra certo come questo universalismo, quando la supremazia tedesca è minacciata, può distorcersi nella barbarie più particolaristica. (6\%)

(10) A Belgrado un nipote dell'impero danubiano dovrebbe sentirsi dentro le proprie frontiere dell'anima, a casa. (81,85\%)

(11) Canettivuol raccontare la genesi dell'Auto da fé, ma non dice veramente nulla di quel libro grandioso né del suo inimmaginabile autore, che dev'essersi trovato sull'orlo della catastrofe e del vuoto. (87,99\%)

Ovde možemo uvideti odstupanje od gorenavedenog pravila, nalazimo upotrebu povratne zamenice si u enklitičkom položaju u 58 primera.

\section{3) Bezlično si (Si impersonale)}

Za bezličnu zamenicu si možemo reći da je Magris upotrebljava u proklitičkom položaju uz modalne glagole. Broj takvih primera je 27. Što se tiče enklitičkog položaja uz modalne glagole nalazimo 7 primera. Na osnovu toga možemo tvrditi da je autor dosledan $\mathrm{u}$ upotrebi bezlične zamenice si u proklitičkom položaju:

(12) Fin da Eraclito, il fiume è per eccellenza la figura interrogativa dell'identità, con la vecchia domanda se ci si possa o no bagnare due volte nelle sue acque $(3,41 \%)$

(13) (...) così si dovrebbe dire che non la successione di quegli attimi senza storia crea storia, bensì le correlazioni e le aggiunte apportate dalla storiografia. $(8,45 \%)$

(14) Gli altri contadini, boschi, parole, consuetudini aldilà dei monti e dei mari, che non si potevano vedere né toccare madi cui si poteva avere una conoscenza solomediata eindiretta,diventavano astratti, ideologici, irreali (...) (9,82\%)

(15) Lo so, tu ami il nulla, e non per il suo minimo valore, bensì perché si può giocare con esso in maniera arguta e lieve (26,05\%)

(16) Senza bollo non si può partire. (99,04\%) 
U narednim primerima stoji jedna bezlična glagolska sintagma koju pisac koristi kada je reč o povratnoj zamenici si u enklitičkom položaju:

(17) Può darsi che la malattia, togliendogli la caparbia forza di scrivere che lo aveva allontanato dalla vita, lo abbia aiutato a trovare quest'ultima, con un'umiltà che la scrittura non gli avrebbe concesso. $(40,38 \%)$

(18) Come accade spesso al caffè, do un'occhiata abusiva al giornale che tiene in mano; forse è quello di oggi, lo stesso che stiamo leggendo noi, può darsi che ogni mattina un cameriere glielo infili tra le dita. $(40,65 \%)$

(19) Può darsi debba disastrosamente chiuderla una terza e definitiva catastrofe, perché due guerre mondiali non hanno sostituito stabilmente l'equilibrio scosso a Sarajevo. $(44,47)$

(20) Può darsi che, in quest'alba, io abbia avuto il mio giorno, come dice re Lear. $(45,02 \%)$

(21) Può darsi quindi che il taccuino danubiano finisca per assomigliare, lungo questo tratto del fiume, alla «prosa in jeans» di quegli autori. (58,66\%)

\section{Pape Satàn Aleppe}

\section{1) Pasivno si (Si passivante)}

Zabeležili smo 37 primera proklitičkog položaja pasivne zamenice si uz modalne glagole:

(22) Come ricordavo all'inizio, le bustine di fiammiferi Minerva avevano all'interno due spazi bianchi su cui si potevano prendere appunti, e pertanto intendevo quei miei interventi come brevi annotazioni e divagazioni sui vari fatti che mi passavano per la testa (...). (2,92\%)

(23) Si sarebbero dovuti abbattere nelle varie piazze d'Italia $i$ monumenti a Garibaldi e cancellare i nomi delle vie intitolate sia a Cavour che a martiri e irredentisti vari. $(6,43 \%)$

(24) E non si dovrebbe caricaturare la Beata Vergine, anche se $i$ 
cattolici fossero (come sono, almeno oggi) alieni dal massacrare chi lo fa. $(51,46 \%)$

(25) Di nuovo si debbono introdurre criteri qualitativi. (65,78\%)

(26) (...) ma a credere di battere chi morde e fugge coi metodi che si dovrebbero usare coi terroristi, del pari si sbaglia. $(66,95 \%)$

Za enklitički položaj pasivne zamenice si uz modalne glagole izdvojili smo sledeće rečenice:

(27) Se la Storia andasse ineluttabilmente nella direzione pensata dal governo, questa forza lavoro dovrebbe riciclarsi altrimenti. (19\%)

(28) Non solo, ma anche l'ora di religione cattolica potrebbe risolversi in uno spazio di discussione etica. $(61,98 \%)$

(29) Se è così, in tutte le persone che vivono a questo mondo (e siamo ben sette miliardi) c'è un germe di follia che può manifestarsi di colpo. $(99,41 \%)$

$\mathrm{Na}$ osnovu datih primera koje smo pronašli u delu, vidimo da Eko češće upotrebljava pasivnu zamenicu si u proklitičkom nego u enklitičkom položaju. Naime, u 37 izdvojenih primera uz modalne glagole autor zamenicu stavlja ispred glagola, dok u samo 3 primera istu nalazimo u enklitičkom položaju.

2) Povratno si (Si riflessivo)

Proklitički položaj povratne zamenice si uz modalne glagole:

(30) Che cosa si potrà sostituire a questa liquefazione? (3,80\%)

(31) In cui tutti si conoscano e si possano riunire facilmente. $(17,54 \%)$

(32) Arriveremo al momento in cui chi non resiste più al rumore si potrà comperare pacchetti di silenzio. (31,28\%)

(33) (...) ma si possono mettere insieme belle raccolte di libri del Novecento rinunciando ogni tanto a una cena in pizzeria. $(72,80 \%)$

Enklitički položaj povratne zamenice si uz modalne glagole:

(34) In ogni caso, pronunciate da Pluto, queste parole confondono le idee, e possono prestarsi a qualunque diavoleria. (2,92\%) 
(35) Ma quante persone ingenue potrebbero mettersi in contatto (...) $(17,25 \%)$

(36) Il cristiano deve sacrificarsi perché gli altri non soffrano e deve fare di tutto perché la quota di dolore che intristisce il mondo sia ridotta il più possibile. $(55,84 \%)$

(37) Si capisce lo sforzo che debbono avere fatto queste pensatrici per potersi affermare. $(43,85 \%)$

Na osnovu prikazanih primera iz knjige zaključujemo da Umberto Eko u svom delu više koristi povratno si u enklitičkom položaju. Povratnu zamenicu si uz modalne glagole pronašli smo u 4 primera u proklitičkom položaju, a za enklitički položaj 61 primer. Na osnovu datih primera, zaključujemo da i Eko koristi povratnu zamenicu si u enklitičkom položaju, kao i Magris. Ovaj odnos prikazan je u Tabeli 1.

\section{3) Bezlično si (Si impersonale)}

Pronašli smo ukupno 23 primera bezlične zamenice si uz modalne glagole u proklitičkom položaju:

(38) Pensiamo alla scienza: si voleva che essa fosse un'ideologia neutra, ideale di progresso comune sia a liberali che a socialisti. $(4,38 \%)$

(39) Ci sono progressi tecnologici oltre i quali non si può andare. $(5,84 \%)$

(40) Si potrebbe obiettare che per una Fiera letteraria, che era l'unico settimanale di lettere e arti che allora un giovane potesse trovare in edicola. $(20,46 \%)$

(41) Spero che non si può partire senza l'attenzione e la epistola mi scrivi. ${ }^{9}(22,80 \%)$

(42) Per quanto mi senta solidale con editori e librai, si potrebbe dire che per le stesse ragioni avrebbero potuto protestare produttori di carrozze. (19\%)

9 Iako bi se očekivao konjunktiv prezenta posle glagola sperare - nadati se, upotrebljen je prezent indikativa. Ova rečenica je deo teksta, mašinski prevedenog, koji Eko prenosi u izvornom obliku. 
Enklitički položaj bezlične zamenice si uz modalne glagole:

(43) Ora, può darsi che tra i milleduecento racconti presentati alcuni fossero di dubbio valore. $(14,91 \%)$

(44) Può darsi che la foto sia stata scelta da qualche sito on line (come quelle degli attori ignoti che appaiono nel cruciverba iniziale della Settimana enigmistica) e dietro a Marina si celi un personaggio che potrebbe interessare Saviano, ma chi lo sa? $(22,80 \%)$

Na osnovu primera koje smo izdvojili iz dela možemo reći da Eko bezlično si dosledno stavlja u proklitički položaj, kao i da je bezlična zamenica si u enklitičkom obliku zabeležena u samo dva primera. Bezlična zamenica si u proklitičkom položaju zabeležena je u 23 primera.

\section{Diskusija}

Istražujući korpus Magrisovog dela Danubio okviran broj primera koji smo tokom analize izdvojili i koji sadrže deo reči ili zamenicu si je 5716. Naravno, potrebno je istaći da se ovde upućuje na tendenciju u upotrebi zamenice, a upravo je ona polazna tačka za dalja istraživanja i tek na kraju za eventualnu generalizaciju. Zamenicu si smo pronašli 22 puta kao pasivnu (i to samo 17 primera uz modalne glagole). Povratna zamenica si javlja se ukupno u 919 primera (uz modalne glagole u proklitičkom položaju javlja se jedanput, a u enklitičkom 58 puta). Upravo je upotreba povratne zamenice u enklitičkom položaju ono što se izdvaja i ne podudura se sa ustaljenim normama italijanskog jezika. Bezličnu zamenicu si pronašli smo 48 puta (uz modalne glagole u proklitičkom položaju pronašli smo 27 primera, a u enklitičkom 7).

Pretražujući zamenice si u Ekovom delu Pape Satàn Aleppe ukupno smo pronašli 6153 primera koji sadrže ovaj deo reči ili pak zamenicu. Od toga smo pretragom zamenice si izdvojili: 35 primera bezlične zamenice si (od toga 23 u proklitičkom, 2 u enklitičkom položaju), 80 primera povratne zamenice si $67 \mathrm{uz}$ modalne glagole - 61 primer u enklitičkom i 6 u proklitičkom položaju) i 41 primer pasivne zamenice si ( 40 uz modalne glagole - 37 u proklitičkom). Na osnovu analiziranih primera i pretpostavke od koje smo krenuli možemo 
reći da je Eko dosledan u svom načinu pisanja i da kako smo naveli bezličnu zamenicu si radije upotrebljava u proklitičkom položaju. Što se tiče povratne zamenice $s i$, autor je stavlja u enklitički položaj, dok pasivnu zamenicu si prema datim primerima radije upotrebljava u proklitičkom položaju. U Tabeli 1 predstavljen je numerički odnos proklitičke i enklitičke upotrebe zamenice si na odabranom korpusu.

Tabela 1. Frekventnost proklitičke i enklitičke upotrebe zamenice $s i$

\begin{tabular}{|l|c|c|}
\hline \multicolumn{3}{|c|}{ Danubio } \\
\hline & položaj zamenice si uz modalne glagole \\
\hline Pasivna & 17 & enklitički \\
\hline Povratna & 1 & 0 \\
\hline Bezlična & 27 & 58 \\
\hline \multicolumn{3}{|c|}{ Pape Satàn Aleppe } \\
\hline \multicolumn{3}{|c|}{ Položaj zamenice si uz modalne glagole } \\
\hline \multicolumn{2}{|c|}{ proklitički } & enklitički \\
\hline Pasivna & 37 & 3 \\
\hline Povratna & 4 & 61 \\
\hline Bezlična & 23 & 2 \\
\hline
\end{tabular}

\section{Zaključak}

Na osnovu prethodne analize možemo reći da su oba autora dosledna u pisanju svojih tekstova u smislu korišćenja zamenice si i to povratne zamenice u enklitičkom položaju, a bezlične i pasivne u proklitičkom položaju. Jedino gde odstupaju od normi jeste položaj povratne zamenice si. Ovom metodom istraživanja uspeli smo da ukažemo na to da se u upotrebi jezika mogu naći različita odstupanja od gramatičkih pravila, što je ovde slučaj sa upotrebom i položajem zamenice si uz modalne glagole. Tokom našeg istraživanja oslonili smo se na elektronski korpus navedenih dela jer je pogodniji za vrstu pretraživanja koju smo sproveli. Ovaj vid analize može biti sproveden i na korpusu dela više autora, pretražujući različite vrste korpusa, a među njima i Internet korpus, čemu ostavljamo prostor za neka buduća istraživanja. 


\section{LITERATURA}

\section{Korpus}

Magris 2006: C. Magris, Danubio. Online, [https://cdn.fbsbx.com/v/t59.2708-

21/145025249_3449744931815527_5323591948065375685_n. epub/Magris-Claudio-Danubio.epub?_nc_cat=111\&ccb=2\&_nc_sid=0cab14\&_nc_ohc=SAsHkA_EX-MAX-Wk89Q\&_nc_ht=cdn.fbsbx. com\&oh=fe14259f49c288a8d9317cdc8e669dff\&oe=60200EFB\&dl=1].

Eko 2016: U. Eco, Pape Satàn Aleppe. Online [https://cdn.fbsbx.com/v/ t59.2708-21/12480781_10208789124234508_2021429309_n. epub/Eco-Umberto-Pape-Sat\%C3\%A0n-Aleppe.Cronache-di-una-societ\%C3\%A0-liquida. epub?_nc_cat $=102 \& c c b=2 \& \_n c \_s i d=0$ cab14\&_nc_ ohc=bumTECcXqSAAX_i09NW\&_nc_ht=cdn.fbsbx.com\&oh=c0a09a94a3be4249db29329b7cc7c15e\&oe=60204A81\&dl=1].

\section{Reference}

Dardano i Trifone 2014: M. Dardano, P. Trifone, La nuova grammatica della lingua italiana. Milano: Zanichelli.

Foljato i Testa 2000: S. Fogliato, M. C. Testa, Strumenti per l'italiano. Riflessione sulla lingua. Torino: Loescher.

Lepski i Lepski 1998: A. L. Lepschy, G. Lepschy, The Italian Language Today. London/New York: Routledge.

Mazini 2015: F. Masini, Idiomatic verb-clitic constructions: lexicalization and productivity. Bologna: Università di Bologna.

Miličević 2009: M. Miličević, Problemi klasifikacije povratnih oblika u italijanskom jeziku i njihove pedagoške implikacije. Anali Filološkog fakulteta, 21, 277-310.

Moderc 2006: S. Moderc, Gramatika italijanskog jezika. Morfologija sa elementima sintakse. Beograd: Luna crescens.

Renci, Salvi i Kardinaleti 2001: L. Renzi, G. Salvi, A.Cardinaletti, Grande grammatica italiana di consultazione, vol. I, La frase. I sintagmi nominale e preposizionale. Bologna: Il Mulino.

Simone i Amaker 1977: R. Simone, R. Amacker, Italian Linguistics: Volume 3: Verbi Modali. Lisse: The Peter De Ridder Press.

Terić 2009: G. Terić, Sintaksa italijanskog jezika. Beograd: Filološki fakultet. 


\section{Jovana Bazić}

\section{L'USO E LA POSIZIONE DEL PRONOME SI CON I VERBI SERVILI}

\section{Sommario}

Nella presente tesi è stato analizzato il pronome si che nella lingua italiana può essere impersonale, riflessivo e passivante. Rispetto al verbo al quale viene associato, il pronome si può cambiare il proprio posto, soprattutto in presenza dei verbi servili. Nelle lingue romanze i clitici derivano dal latino. Durante il loro sviluppo hanno cambiato la posizione ma anche le funzioni. Il clitico si di cui ci occupiamo nella nostra tesi può avere diverse posizioni che in questo contesto abbiamo cercato di evidenziare. La grammatica italiana ci mostra la posizione del pronome $s i$ secondo le norme. Qui abbiamo voluto vedere se gli autori summenzionati abbiano rispettato le regole nei loro capolavori siccome si tratta proprio della letteratura italiana nella quale, ovviamente, abbiamo trovato alcune eccezioni. Lo scopo principale è stato quello di evidenziare la coerenza, la posizione e infine l'uso del pronome suddetto. Parlando però dei clitici e pronomi abbiamo menzionato anche i verbi servili e il loro ruolo quando si parla dei clitici in italiano. Utilizzando il corpus elettronico di due libri Danubio e Pape Satàn Aleppe ed elencando l'intero numero delle posizioni proclitiche e enclitiche abbiamo evidenziato che tutti e due autori usano il pronome si nella stessa maniera, lo scrittore Eco infatti è conseguente nel suo modo di scrivere e che, come abbiamo già detto si impersonale è posto nella posizione proclitica; si riflessivo nella posizione enclitica e infine si passivante nella posizione proclitica. Lo stesso possiamo dire anche per il secondo scrittore. Il risultato della presente analisi è l'attestazione delle suddette regole quando parliamo del pronome si impersonale e passivante, mentre non possiamo dire lo stesso anche per il pronome riflessivo che viene usato nella posizione enclitica. In conclusione, esplorando il nostro corpus abbiamo creato lo spazio ulteriori ricerche sul pronome si nei diversi corpus, includendo anche la ricerca vastissima su rete Internet.

Parole chiave: lingua italiana, si passivante, si riflessivo, si impersonale, verbi modali. 